\title{
TÓPICA LITERARIA Y REALIZACIÓN TEXTUAL: UNAS NOTAS SOBRE LA POESIA ESPAÑOLA DE LAS RUINAS EN LOS SIGLOS DE ORO
}

El idóneo abordaje crítico de los textos literarios es cuestión siempre candente y ante la que no existen - tal vez por imposibilidad radical- respuestas satisfactorias. Estas suelen ser unidireccionales; y lo son por su propia coherencia metodológica. El asunto lleva aparejado además una dificultad que atañe al punto de partida: algunos muy certeros análisis son imposibles de extrapolar desde su concreta realización a una consideración abstracta del proceso; y, por el contrario, cuanto más completa sea una teoría, más difícil suele resultar su aplicación. Pero ese lastre inicial tiene una fácil justificación: las más de las veces para elaborar una teoría se opera con abstracciones que emergen de experiencias múltiples y alejadas, objetivadas en la comunidad de conocimientos que constituye grosso modo la crítica literaria. Por el contrario, cuando se opera desde análisis concretos, el techo de abstracciones viene marcado necesariamente por el límite preciso que impone el texto. De modo que el problema queda siempre aparcado en ese espacio intermedio, tierra de nadie, ocupada esporádicamente por una u otra de las proyecciones señaladas.

Cada acercamiento crítico a un texto es una experiencia distinta. De ahí la afirmación generalizada de que cada texto determina su propio análisis. Es ya como un axioma de uso común cuya base racional es la obviedad. Pero me parece que esta obviedad puede ser interpretada desde dos vertientes: una, la que le corresponde estrictu sensu, 
por la pura evidencia casi pueril; y otra, por el enmascaramiento de una carencia, esto es, de una metodología crítica.

De todos modos, tampoco es exactamente cierta aquella afirmación. El crítico lleva incorporado un bagaje, producto de una selección de cuantas teorías y aproximaciones al comentario de textos su curiosidad le haya llevado a conocer. Esa selección determina puntos de mira específicos. Me atrevería a afirmar que es un proceso depurador en el que se desmontan muchas parafernalias metodológicas en pro de la eficacia y con un proceder, las más de las veces, ecléctico. Se tiene finalmente la convicción de que todo es mucho más sencillo por mucho más complejo. Quiero decir: el texto es virtualmente riquísimo, y así, por paradoja, cuanto más exhaustivo sea un esquema -al fin y al cabo siempre formalista- menos abiertas se dejan sus posibilidades.

Queda claro, por otra parte, que el afán de aprehender esquemas o modelos es no sólo algo legítimo, sino quizás la única vía -0 al menos la más rigurosa- para interpretar el legado literario y para ordenarlo en su evolución. Por eso resulta una perogrullada hablar de la deseable flexibilidad de todo acercamiento crítico-formalista, pues desde el momento en que una obra literaria se constituye como una organización única e irrepetible, comprendemos que la mayor operatividad de los modelos consiste en que ponen de manifiesto los elementos rebeldes como genuinamente caracterizadores de la obra en cuestión.

La historia de la literatura es la historia de los significantes. Pero la organización de éstos produce una determinada significación a partir de la cual dimana un mundo de sentidos proyectados. Estos son creaciones del lector, respuestas al «siencio de la obra, del que hablaba Sartre, y -como vieron los glosemáticos- actualizaciones que nunca agotan todo el potencial significativo del texto. Dependiendo del nivel de lectura, del acervo cultural y de un sinfín de etcéteras, se profundizará más o menos, siempre -e inevitablemente- poniendo más énfasis en determinados aspectos y obviando otros. En toda lectura - sin dejar de ser perfectamente responsable - hay preferencias y legítimos intereses, de orden personal o histórico, éstos especialmente notorios en obras alejadas en el tiempo. La mentalidad e ideología de una época se nos manifiesta a través de los textos conservados, que, en un proceso dialéctico de compromiso con la realidad, son también los responsables de aquéllas. Porque desde la perspectiva siempre anacrónica del lector o crítico posterior, se tiende a ver la literatura como «reflejo», cuando en buena medida es *agente», tanto si se trata de utilizar la ficción como vehículo de ideologias, en una actitud suasoria, más o menos velada dependiendo de la perspicacia del autor, cuanto si éste se sirve de la ficción como 
denuncia para desmontar y censurar la oficialidad vigente, agudizando en este caso, además de la perspicacia, la cautela.

Está claro, por lo demás, que el significado de una obra literaria adquiere su más plena dimensión en las estructuras semiológicas de la cultura que acoge. Tal ubicación resulta tan necesaria que su carencia lleva implícito el riesgo de traicionar - por puro e involuntario anacronismo- aquel significado, actualizando unos sentidos que tal vez en el momento de la interpretación estén cargados de un supuesto «sentido» histórico, pero que desde luego desvirtúan su significación original, para llegar a la cual el único camino lógico — vía de la información- es intentar el ajuste entre los dos sistemas sincrónicos diferentes: el del autor y el del lector. Claro está que conseguirlo plenamente es pura ilusión, pues la reconstrucción del contexto extraviado es una mera cuestión de criterio, hasta donde se quiera llegar ${ }^{1}$.

El texto literario es el signo resultante de un proceso de formalización de sustancias, tanto de expresión como de contenido ${ }^{2}$. En el pri-

1 Tiene razón al afirmarlo así Jürgen Trabant, pero no tanta al decir que en ese punto el comentarista procede con absoluta arbitrariedad, casi con la misma que el poeta, puesto que éste presupone de antemano ciertos conocimientos en los lectores (Semiologia de la obra literaria, Madrid, Gredos, 1975, pág. 245). Bl crítico reconstruye el contexto con arreglo a los puntos de interés que quiere destacar; por tanto no es arbitrario, sino unilateral. $Y$ por este mismo matiz, entre otros, resulta impertinente la comparación con el autor.

2 Como puede observarse, la terminología aquí empleada es coincidente con la utilizada por las aplicaciones de la teoría glosemática a la crítica literaria. Sin embargo, el concepto que más me interesa (la forma del contenido) presenta discrepancias importantes con aquel proceder metodologico, según explico a continuación. A partir de la teoría de Hjelmslev sobre los sistemas de signos «connotativos* (es decir, aquellos cuyo plano de la expresión está formado por un signo completo, con sus niveles respectivos de contenido y expresión), sus discípulos STENDER-PETERSBN («Esquisse d'une théorie structurale de la littérature», en Recherches Structurales, Copenhague, 1949, págs. 277-287) y JoHANSEN ( $\times$ La notion de signe dans la glossématique et dans l'esthétiquex, en Idem, págs. 288-303) hicieron la aplicación al signo literario. La aplicación resultó fecunda por varias razones. Hacía más evidente, o formulaba, algo ya sabido: el nuevo status que adquiere la lengua en el texto artístico, del que constituye su plano de la expresión; asi, el estudio de este no puede prescindir de ninguno de los elementos que constituyen un signo completo. Además esta teoría proponía un exhaustivo análisis de la obra literaria, pues a los dos niveles se agregaban las nociones de forma y sustancia, produciéndose cuatro estratos: sustancia de la expresión, forma de la expresión, forma del contenido y sustancia del contenido. De todos ellos, el estrato forma del contenido es el que presenta una falla más importante, hasta el punto de quedar un tanto desdibujado, contradiciendo, además, en su análisis el proceder somasiológico (del significanto al significado) que afirman seguir en todo el proceso. Johansen vio la posibilidad de dividir la obra en unidades interpretativas que venian marcadas por la tntuicion de unidades connotativas. Por tanto aquí están operando desde el significado al significante. $Y$ éste es -creemos- el único camino. Se debe proceder, pues -y a nuestro modo de ver- en un criterio dialéctico (entre contenido y expresión) y

LXVI, $1.0-2.0-5$ 
mer caso se procede con un tipo de análisis retórico, estilístico o como a bien tenga denominarse, operando con un criterio paradigmático a partir de una retórica normativa, o sintagmático - que ha venido a demostrar el error del anterior procedimiento- a través de la descripción de los elementos interrelacionados. Más difícil y sutil es ver el proceso de formalización de los contenidos, hasta el punto de cuestionar su posibilidad. Pero la experiencia (la observación empírica de los textos, si se me permite la expresión) nos hace ver la vinculación de determinados contenidos a determinadas formas preferentes. Son ahormaciones previas a la realización de la obra, en un repertorio de posibilidades del que puede servirse el escritor (no son, por tanto, sólo apreciables a posteriori; por eso el crítico remeda en cierta manera el proceso creador). En esta perspectiva encajan los géneros literarios, como condicionamientos formales asociados a la expresión de determinados contenidos. Son, pues, lugares comunes, pero tan flexibles como el genio individual de cada escritor sea capaz de transformar. Y en esa mediatización del contenido hacia su formulación textual entra la tópica, en un nivel de realización distinto al del género. Es más amplia y por tanto poligenérica. Pero al mismo tiempo cristaliza en formulaciones linguísticas asociadas a un determinado género, surgiendo así subgéneros específicos claramente aislables. Es el caso de la poesía de las ruinas en los siglos XVI y XVII, donde hay una evidente relación de reciprocidad género $\leftrightarrow$ tópica.

Los textos literarios que hacen uso de la tópica como elemento fundamental presentan un peculiar carácter, pues al acoger en su proceso constitutivo elementos que han sufrido previamente una formalización, actualizada incluso en estilemas (que se manifiesta tanto en léxico como en fórmulas sintácticas o configuraciones metafóricas), el texto debe adquirir un diferente estatuto de originalidad del que carece el resto, cuya condición de original se da por atributo genésico. La clave está en la distribución de las piezas. Variado al cien por cien el concepto de imprevisibilidad (atributo esencial, para Riffaterre ${ }^{3}$ por ejemplo, del texto literario), lo imprevisible debe ser la impostación de esos elemen-

convergente (de las sustancias a las formas en ambos niveles). Con este criterio convergente se llega al punto más importante, al estrictamente peculiar del texto literario: el engranaje entre la forma de la expresión y la forma del contenido. Precisamente aquí es donde entra la peculiaridad de los textos que hacen uso de la tópica como elemento integrante en su configuración.

3 Micanal RIfpaterre, Ensayos de estiltstica estructural, Barcelona, Seix Barral, 1976. 
tos, más que previsibles, en su contexto, para producir un efecto diferente $y$, en consecuencia, hacer evolucionar el tópico.

En los textos poéticos españoles de los Siglos de Oro nos encontramos con la presencia profusa de un motivo: las ruinas, presencia que se vehicula en formas recurrentes fácilmente identificables. La erudición positivista ${ }^{4}$ aclaró desde hace tiempo los orígenes de la introducción del motivo en la poesía española, que, por lo demás, se presentó bien fácil en este caso. Fue Gutierre de Cetina (que tantas novedades trajo de la mano del italianismo en la complementación de un universo poético hecho ya literatura española por Garcilaso) quien lo hizo espanol por la imitación del soneto de B. Castiglione «Superbi colli, e voi sacre ruine» en el suyo:

Excelso monte do el romano estrago

eterna mostrará vuestra memoria;

soberbios edificios do la gloria

aún resplandece de la gran Cartago;

desierta playa, que apacible lago

lleno fuiste de triunfos y victoria;

despedazados mármoles, historia

en quien se ve cuál es del mundo el pago;

arcos, anfiteatro, baños, templo,

que fuistes edificios celebrados

y agora apenas vemos las señales;

gran remedio a mi mal es vuestro ejemplo:

que si del tiempo fuistes derribados,

el tiempo derribar podrá mis males 5 .

4 A. Morel-Fatio, «Histoire de deux sonnets», en Etudes sur l'Espagne, Paris, 1904, III, págs. 141-161; R. Foulchí DelBosc, «Notes sur le sonnet Superbi colli», Revue Hispanique, XI, 1904, págs. 225-243; J. FucIL1A, «Notes sur le sonnet Superbi colli (Rectificación y suplemento)», Boletín de la Biblioteca Menéndez Pelayo, XXXI, 1955, págs. 51-90; J. FucIlLA, «Superbi colli» $e$ altre saggi. Notas sobre la boga del tema en España, Roma, Carucci, 1963. Por lo demás, el tema de las ruinas ha sido objeto de una relativamente extensa bibliografía que incide en aspectos filosóficos o filológico-literarios. Caben ser destacados los estudios de E. Orozco Dthz, «Ruinas y jardines: su significación y valor en la temática del Barrocon, en Temas del Barroco, Granada, 1947; J. STaRobinski, «La mélancolie dans les ruines», en L'invention de la liberté, Paris, 1964; P. ZICKkr, Fascination of Decay, Ridgewood, 1968; B. WardROPPER, "The poetry of Ruins in the Golden Age», Revista Hispdnica Moderna, XXXV, 1969, págs. 295-305; R. MortikR, La poétique des ruines en France, Ginebra, 1974; J. Lara Garrido, «Notas sobre la poética de las ruinas en el Barroco», Analecta malacitana, IV, 1981, págs. 385-99; del mismo, «El motivo de las ruinas en la poesía espaniola de los siglos xVI y XVII (Funciones de un paradigma nacional: Sagunto)n, en Idem, VI, 1983, págs. 223-77.

3 GutizRrB dB CBtina, Sonetos y madrigales completos, ed. de B. López Bueno, Madrid, Cátedra, 1981, pág. 210. 
Las claves significacionales ya están dadas: oposición entre un pasado glorioso y la destrucción presente; y la extrapolación del motivo para aplicación personal de consuelo ("gran remedio...»). El modelo italiano facilitaba ambas cosas. Para la exposición del motivo, la descriptio de los fragmenta arquitectónicos: «Theatri, archi, colossi, opre divine, / triomphal pompe gloriose a liete»; y la explícita consolatio: «che se'el tempo da fine a ciò che'è in terra, / darà forsi anchor fino al mio tormento".

Curioso resulta, sin embargo, que si Castiglione se refería a las ruinas de Roma, Cetina traslada la visión a Cartago, en un trasplante que tendrá gran éxito entre los españoles. Varias hipótesis se pueden manejar al respecto. Tal vez el recuerdo de Garcilaso en su soneto a Boscán desde la Goleta. Allí el pensamiento amoroso atormenta al poeta en medio de la contemplación de las ruinas:

Aquí donde el romano encendimiento, donde el fuego y la llama licenciosa sólo el nombre dejaron a Cartago,

vuelve y revuelve amor mi pensamiento, hiere y enciende el alma temerosa, $y$ en llanto y en ceniza me deshago 6 .

Es también posible que las ruinas de Cartago llamaran directamente la atención de Cetina y de otros poetas-soldados en las expediciones mediterráneas de Carlos V. O finalmente cabe pensar que los españoles de la época imperial prefirieran no aludir a las ruinas de Roma, cuyo saco en fechas recientes tal vez levantara ampollas, y en todo caso era mejor evitarlo.

Si alguna vez se ha criticado el fácil positivismo que explota la línea del Superbi colli a través de la mediación de Cetina, lo cierto es que resulta ser la más segura y evidente. El soneto de Cetina se hizo famoso, como lo prueba la imitación de Manuel Ledesma, aplicando ahora el motivo a las ruinas de Sagunto:

Sagunto insigne do el sangriento estrago ha de mostrar eterna tu memoria,

- Garciuso dB LA VBGa, Obras completas con comentario, ed. de E. L. Rivers, Madrid, Castalia, 1974, págs. 152-3. (En pro de una uniformidad en este trabajo, modernizamos las grafias en todas las citas textuales.) Por cierto que este soneto de Garcilaso, aunque encabece algunas antologias sobre poesia de ruinas (cfr., por ejemplo, S. B. Vranich, Los cantores de las ruinas en el Siglo de Oro, Ferrol, Esquio, 1981) no es propiamente tal: en el las ruinas son un marco de presencia y no un motivo significacional. 


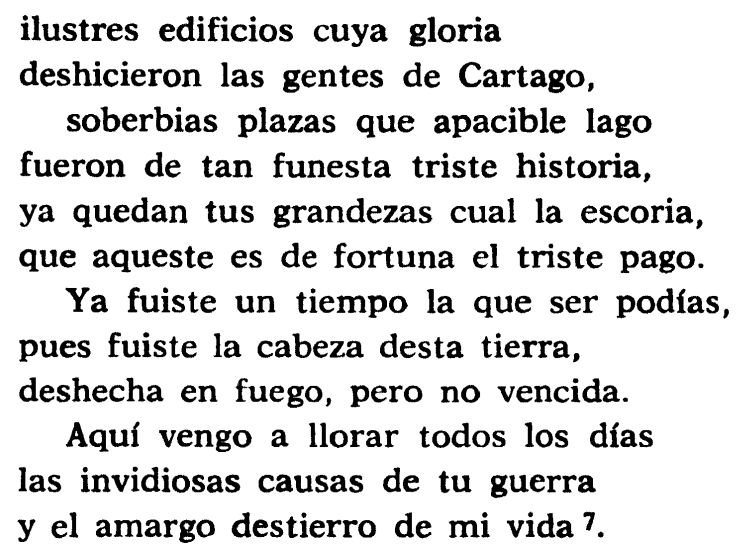

Las semejanzas en los cuartetos son notorias. Ahora bien, se trata de una imitación aparencial, tanto en el motivo en sí (Cartago no es ahora la víctima, sino el agresor), como en su aplicación (de la consabida consolatio amorosa a la reflexión sobre las propias miserias, reflexión que si queda aquí un tanto deshilvanada - necesario cierre final-es indicativa de una evolución posterior por ese camino). Pero el soneto de Ledesma tiene otro particular interés, en cuanto que dibuja ya el símbolo que representará Sagunto («deshecha en fuego, pero no vencida") como un ejemplo ético de la fidelitas ${ }^{8}$. Por eso Lupercio Leonardo de Argensola, en un conocido soneto, invoca la memoria de unos «Muros, ya muros no, sino trasunto", correlatos de su propia trayectoria sentimental y deseado cobijo:

De hoy más juntos los vuestros y mis males

se cuenten; pues la fe perpetua y pura

y el tiempo los ha hecho tan iguales.

$Y$ pues os ha dejado la ventura

memoria y sepultura de leales,

dadme también memoria y sepultura?.

Pero el soneto de Cetina iba a marcar otra más fértil descendencia. Y no a través de la directa imitación en este caso, sino como la iniciación de un género de particular eco entre los sevillanos. Fue de capital

7 Cancionero de la Academia de los Nocturnos de Valencia, extractado de sus actas originales por don Pedro Salvá y reimpreso con adiciones y notas de Francisco Martí Grajales, III, Valencia, 1906, pág. 57.

8 En las sucesivas recreaciones poéticas, Sagunto (con su confiada espera durante el asedio de la ayuda de su aliada Roma, que nunca llegó) se perfila como un modelo ideal de conducta frente a criterios objetivos y pragmáticos: «signo de un comportamiento ético-político antípoda de la tacitista 'razón de estado'" (J. LARA, «El motivo de las ruinas...», art. cit., pág. 234).

- Rimas de Lupercio y Bartolomé Leonardo de Argensola, ed. de J. M. Blecua, I, Zaragoza, 1950, pág. 56. 
importancia el hecho de que Herrera lo recogiera en sus Anotaciones a Garcilaso, teniendo en cuenta que este libro se va a convertir en un crisol de conocimientos, a más de florilegio de poetas andaluces, del que se nutrirán sus paisanos humanistas y poetas. El mismo Herrera se aplicará a poetizar sobre las ruinas en diversas composiciones y con varios fines ${ }^{10}$. Pero sobre todo modelará un soneto cuya fama viene más de la amplia acogida entre sus seguidores en las respectivas composiciones a Itálica, que por sus propios valores poéticos:

\footnotetext{
Esta rota y cansada pesadumbre, osada muestra de soberbios pechos; estos quebrados arcos y deshechos, y abierto cerco de espantosa cumbre, descubren a la ruda muchedumbre su error ciego y sus términos estrechos; y sólo yo en mis grandes males hechos, nunca sé abrir los ojos a la lumbre.

Pienso que mi esperanza ha fabricado edificio más firme, y aunque veo que se derriba, sigo al fin mi engaño.

¿De qué sirve el juicio a un obstinado que la razón oprime en el deseo? De ver su error y padecer más daño 11 .
}

La descripción de los fragmenta cuaja en unos sintagmas característicos (la «rota y cansada pesadumbre», los «quebrados arcos y deshechos», y sobre todo la patética referencia al anfiteatro «abierto cerco de espantosa cumbrex) que pasarán en buena medida lexicalizados a las recreaciones sucesivas. $Y$ desde luego la fórmula def́ctica inicial, con la expresión de una inmediatez que animiza, por su verismo, la contemplación angustiada. Esta fórmula (complicada por la interposición entre el demostrativo y el sustantivo de un determinativo) se convertirá en la carta de identidad de las recreaciones de los sevillanos sobre Itálica: «Estos de pan llevar campos ahora" comienza el soneto de Francisco de Medrano, «Esta, a la rubia Ceres consagrada» el de Juan de Arguijo, «Estas ya de la edad canas rüinas» el de Francisco de Rioja; y desde luego la famosa canción de Rodrigo Caro «Estos, Fabio, jay dolor!, que ves ahora». A su difusión contribuyó Góngora en su comienzo del Polifemo («Estas que me dictó rimas sonoras»), pero indudablemente

10 Cfr. G. Cararno Porras, wDel paradigma clásico a una apertura significacional en el motivo de las ruinas a través de la poesía de Herrera», Analecta malacitana, IV, 1981, págs. 309-29.

11 Ferrundo dB Herrera, Poesía castellana original completa, ed. de C. Cuevas, Madrid, Cátedra, 1985, pág. 451. 
en la conciencia artística del momento iba asociada al estereotipo del motivo de las ruinas. Así se explica que en la liquidación de aquél por Quevedo en su formidable silva $A$ los huesos de un rey que se hallaron en un sepulcro, ignorándose, y se conoció por los pedazos de una corona -sobre la que volveremos- comience "Estas que veis aquí pobres y escuras".

Son los sevillanos de fines del xVI y principios del XVII, los poetas eminentes y los menos, quienes forjan de manera definitiva el tópico encauzándolo en la visión de la antigua ciudad romana cercana a Sevilla. Y lo hacen en el seno de una poesía que reflexiona preocupadamente sobre la vida y que propone un código de comportamiento basado en el ejercicio de la virtus estoica. Junto a Horacio, la moral senequista conformará el idearium de una poética ejemplarmente concretada en la Epistola moral a Fabio, en las silvas de Rioja a las flores y, de manera especial, en la poesía de las ruinas. Ante su presencia incitante, Itálica se convierte en un tema en boga en el que parecen competir estos sevillanos. Así lo testimonia Hernando de Soria en su epístola a Lucas de Soria:

Tan adelante en esto ha caminado cual suele nuestro vago pensamiento que el sitio ha ya y lugar determinado.

Será, pues, si te place, aquel convento que tres millas de la gran ciudad vecina tiene, y sobre un collado hermoso asiento, do ve el mudo silencio la rüina de Itálica deshecha que conserva rastros de la alta majestad latina,

y el grande anfiteatro a quien reserva forma el tiempo y asientos levantados, mas cubiertos de malva y de vil yerba.

Acuérdome de estar allí asentados muchas veces Medrano y yo viniendo de su hacienda, cerca aunque cansados,

y alguna solitaria cabra viendo pacer aquel teatro que algún día tanta gente vio en sí y festivo estruendo,

de aquella muda soledad salía concento y voz que nos hablaba clara y que a filosofar nos persuadía 12.

12 A. Rodrfguez MoNino, «Hernando de Soria Galvarro (dos poesías inéditas)», en La transmisión de la poesía española de los Siglos de Oro, Barcelona, Ariel, 1976, páginas 153-4. 
Y filosofar poético fueron las realizaciones al respecto. Había que apurar en un margen estrecho de posibilidades buscando eficacia estética que coadyuvara en la expresión del exemplum de la fugacidad del tiempo, con su consiguiente estela del desengaño y de la vanitas. Es la aplicación que, por su frecuencia, se trivializa en las mediocres realizaciones de un Fernando de Guzmán ( Vi de la grande Itálica famosa...») o de un Juan de Espinosa ( Itálica infelice que del hado...»), para venir a encauzarse por el interrogante Ubi sunt -nunca más gratuito el engranaje de dos tópicos- en Pedro de Quirós («Itálica ¿dó estás? Tu lozanía...») o Francisco de Villalón («... Itálica infelice ¿dó la cumbre? / ¿Dó está la majestad? ¿El inhumano anfiteatro dónde?...»). Pero también surgen hallazgos. Así el sobrecogedor final de Rioja:

$Y$ ya el fausto y la pompa lisonjera

de pesadumbre tan ilustre y rara

cubre yerba y silencio y horror vano ${ }^{13}$.

O de Medrano; las piedras ruinosas, pero erguidas, son ejemplos de dignidad:

Pues si vencen la edad y los extremos del mal, piedras calladas y sufridas, suframos, Amarilis, y callemos 14.

Mayor eficacia expresiva logran - a mi modo de ver- estos sonetos que la archiconocida canción de Caro, con versos también imponentes como éstos:

Este despedazado anfiteatro,

impio honor de los dioses, cuya afrenta

publica el amarillo jaramago,

ya reducido a trágico teatro,

joh fábula del tiempo!, representa

cuánta fue su grandeza y es su estrago 15.

La «fábula del tiempo»: esa es la raíz del motivo, que con el centrarse progresivo en sí mismo, va perdiendo la cáscara del tópico para llegar a la esencia del símbolo. «Fábula del tiempo», pero con soluciones di-

13 Francisco de Rioja, Poesía, ed. de B. López Bueno, Madrid, Cátedra, 1984, páginas 200-1.

14 Vida y obra de Medrano, II, ed. crítica por D. Alonso y S. Reckert, Madrid, CSIC, 1958, pág. 148.

15 De las cinco redacciones que tuvo esta canción, estos versos corresponden a los 18-23 de la última y definitiva (cfr. P. Blanco SuArez, Poetas de los siglos XVI y XVII, Madrid, Instituto Escuela, 1923, págs. 297-302). 
versas. En esos estrechos márgenes en que hay que buscar la originalidad, Arguijo invierte los términos:

Esta, a la rubia Ceres consagrada parte fecunda de la madre tierra, que el sustento común al orbe encierra de tanta espiga en la preñez dorada,

fue ciudad al comercio dedicada, que la quietud y la verdad destierra, duro después teatro de la guerra, que toda en sangre la dejó bañada.

Del primitivo asunto restaurado, gracias rinde en el fruto repetido al circular precepto de los meses;

también siéndole el tiempo agradecido no más hierro la hiera que el arado, no más peso la oprima que sus mieses ${ }^{16}$.

El eje significativo se va centrando, pues, en el motivo mismo como representación simbólica del tiempo, destructor las más veces, benéfico en ocasiones. Y paralelo a ese proceso va la progresiva desaparición de la consolatio, en un repudio de los ejemplos externos frente al drama existencial íntimo. Una vez más la voz de Arguijo:

No los mármoles rotos que contemplo, tristes reliquias de la gran Cartago, ni de Numancia el miserable estrago, ni los despojos del efesio templo; no de Sagunto el fin, único ejemplo de la lealtad y de su injusto pago, descrecen mi dolor, ni satisfago con su memoria al mal que nunca templo.

Bien que prueba tal vez la fantasía, aunque en vano, aliviar mi desventura con la grandeza de desdichas tales;

mas la razón advierte que confía en remedio engañoso quien procura con los ajenos consolar sus males ${ }^{17}$.

16 JUAN DE ARguijo, Obra poética, ed. de S. B. Vranich, Madrid, Castalia, 1971, página 151. Las composiciones a Itálica, que forman el conjunto más homogéneo desde el punto de vista formal, ponen de manifiesto, en su heterogeneidad de sentidos, la polivalencia significativa del motivo, frente a otros paradigmas nacionales (Sagunto o Numancia) que llevan asociado un simbolismo ético-politico derivado de su propia historia.

17 Ed. cit., pág. 149. 
Pero ésta será sólo la liquidación expresa de una consolatio erudita. La eficacia viene de la mano del patetismo de Quevedo, en un soneto cuyo último verso sintetiza - a modo de lema- el más angustioso sentido de la temporalidad:

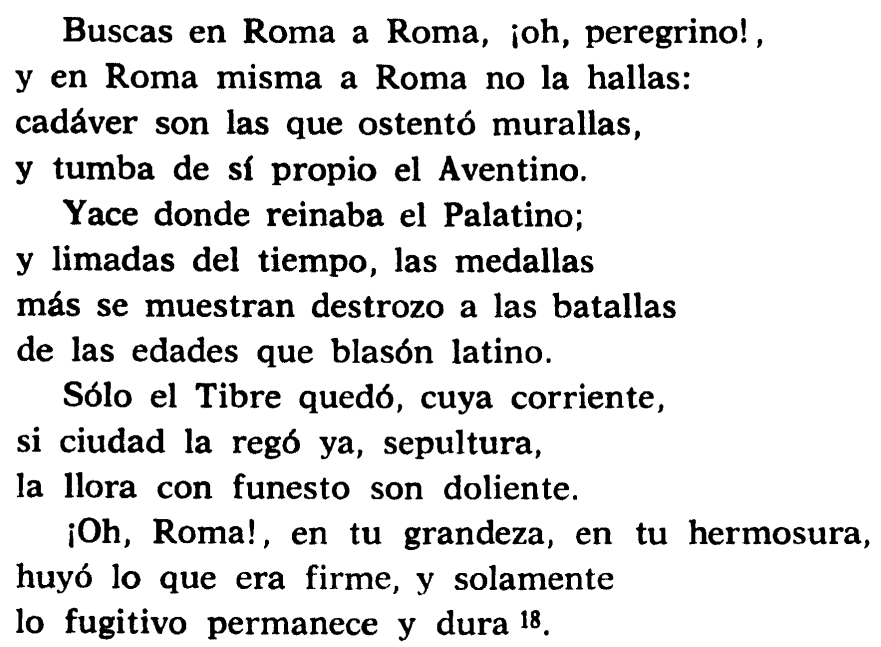

La res histórica no sólo se minimiza, sino que se aniquila. Importa sólo en virtud de su destrucción, como «trofeo del tiempo», el gran protagonista, y las ruinas, el gran testimonio. Significativa evolución la sufrida por este motivo. El Renacimiento descubrió las ruinas con el orgullo humanista de ver en ellas un proceso histórico de fases cambiantes. Los poetas amorosos petrarquistas hicieron una trivial -cuando no extravagante - aplicación a su propio devenir sentimental. Pero el motivo no podía ser fundamental en un momento histórico que cantó al «ser» en su animismo esencial y acrónico (raíz del mito bucolista). Será la preocupación, y la angustia subsiguiente, por el «estar» del hombre en el mundo, tan intensamente percibida por los hombres barrocos, la que lo hará consustancial con su expresión poética. Los espíritus sensibles buscarán un reducto en su propia interioridad, fijándose en los modelos literarios que les sirvan para encauzar su salvación personal «a pesar de todo». Y ahí están las ruinas, ejemplos al mundo de glorias que pasan. De ello extrapolan -aprovechando el diseño formal de aplicación amorosa, pero con bien distinta intención- la lectio: ejercitarse en el ejercicio de la virtus y resistir tan callada y dignamente como las propias piedras. Pero finalmente las ruinas serán sólo expresión de sí mismas. Ya no es posible diferenciar significación textual y sentido adicional. Todo es lo mismo porque es símbolo. Asistimos así a un curioso proceso inverso al normal. De un tópico de raigambre erudita

18 Francisco de Quevedo, Obra poética, I, ed. de J. M. Blecua, Madrid, Castalia, 1969, pág. 418. 
al símbolo definidor de un momento histórico. $\mathrm{Y}$ al tiempo que se vitaliza, se dignifica estéticamente: no es una excusa "para», sino la expresión «de».

Pronto se derivará hacia la pendiente de la espectacularidad terrorifica, convirtiéndose las ruinas en habitáculos de macabras marchas de gusanos. Con jocosa mordacidad Quevedo se sirve del motivo para expresar el poder igualador del tiempo-muerte. De la magnificencia de un sepulcro real sólo se tiene noticia por los pedazos de una corona:

Estas que veis aquí pobres y escuras ruinas desconocidas, pues aun no dan señal de lo que fueron; estas piadosas piedras más que duras, pues del tiempo vencidas, borradas de la edad enmudecieron letras en donde el caminante junto leyó y pisó soberbias del difunto.

¡O muerte, cuánto mengua en tu medida la gloria mentirosa de la vida! ${ }^{19}$.

El ansia devoradora del tiempo se ceba en las glorias de antaño ofreciendo esqueletos de difunto. En las torres de Joray -estamos ahora en un romance también de Quevedo-:

Las dentelladas del año, grande comedor de mundos, almorzaron sus almenas y cenaron sus trabucos.

Donde admiró su homenaje, hoy amenaza su bulto: fue fábrica y es cadáver; tuvo alcaides, tiene búhos.

Certificóme un cimiento que está enfadando unos surcos, que al que hoy desprecia un arado, era del fuerte un reducto.

Sobre un alcázar en pena, un balüiarte desnudo mortaja pide a las yerbas, al cerro pide sepulcro.

Como herederos monteses, pájaros le hacen nocturnos las exequias, y los grajos le endechan los contrapuntos.

19 Idem, págs. $275-7$. 


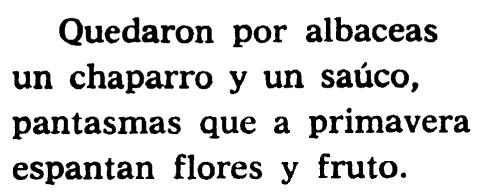

De ahí la lección:

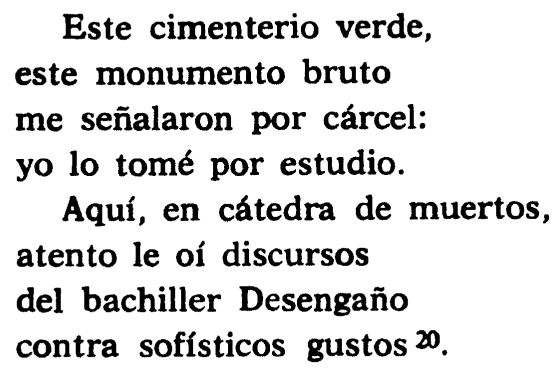

Esa es la única y absoluta verdad. Todo lo demás (buscar consuelo también) son «sofísticos gustos». Más allá incluso de la impresión terrorífica, priva la mirada despiadada. En multitud de textos anónimos del xvir se repiten, no sin gracejo, cuadros de ruinas como fantasmagóricas arcas de Noé pobladas de cernícalos, cuervos o mochuelos. Bien cerca quedaba ya la mirada cáustica. Y ningún maestro como Góngora en ella. Tan demoledor como el tiempo, la lengua del cordobés contra el viejo Castillo de San Cervantes:

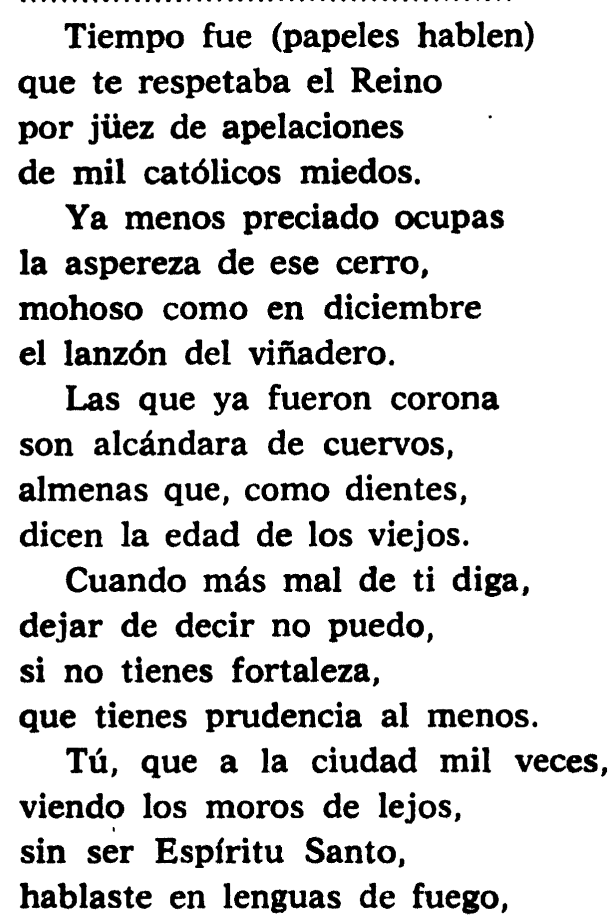

20 Idem, III, 1971, págs. 647. 


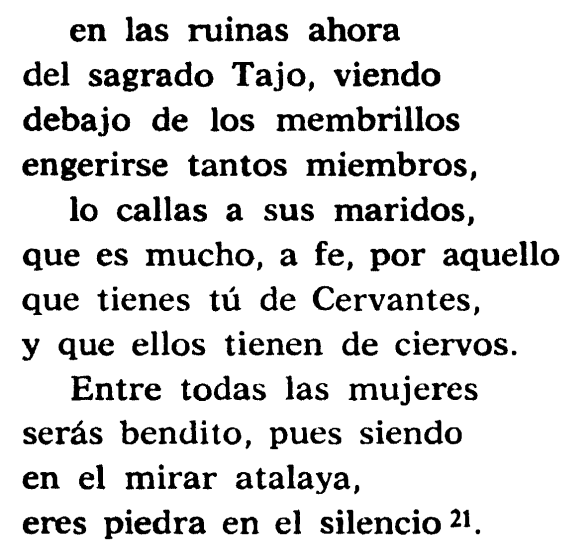

Lejos de la digna y callada serenidad, del ruinoso orden, asistimos a la visión degradada del ruinoso desorden, visión de un mundo tambaleante presidido por la inestabilidad.

Pero, claro está -y como apreció Maravall 22-, si los barrocos tenían conciencia de desorden, es porque presentían el orden, si el mundo está al revés, es porque tiene un derecho. Ahí radica la clave del Barroco: si poéticamente intuyeron ese ser preheideggeriano, si fueron existencialistas «avant la lettre", en el fondo estaban inmersos en una concepción sustancialista del mundo. Ante tal conflicto sólo cabía una salida, el fatalismo, que en su dinamicidad es, paradójicamente, inmovilista.

Nada mejor para acercarnos a un momento histórico que hacerlo a través de su tópica, que presta formas a los contenidos. Así vemos que los del Barroco dan la mayor lección de inmovilismo. ¿Qué decir del gran teatro del mundo? Pero las ruinas no le van a la zaga. Es una desvalorización del mundo, de sus pompas..., una aceptación de su fatalismo histórico. Ese es el elemento radical del motivo. Independientemente de que de él se pueda sacar una lección de consuelo como aceptación resignada («el «suframos, Amarilis, y callemos») o la constatación terrible de la desolación en un Quevedo. La ruina no sólo afecta ya a lo materialmente arruinable; su propio interior también lo es:

Miré los muros de la patria mía, si un tiempo fuertes, ya desmoronados, de la carrera de la edad cansados por quien caduca ya su valentía.

Salíme al campo, vi que el sol bebía los arroyos del yelo desatados, y del monte quejosos los ganados, que con sombras hurtó su luz al día.

21 Lurs de Goncon, Romances, ed. de A. Carreño, Madrid, Cátedra, 1982, pars. 233-6.

22 J. A. Maravall, La cultura del Barroco, Barcelona, Ariel, 1980, pág. 366 y sige. 
Entré en mi casa; vi que, amancillada, de anciana habitación era despojos; mi báculo, más corvo y menos fuerte; vencida de la edad sentí mi espada. $Y$ no hallé cosa en que poner los ojos que no fuese recuerdo de la muerte ${ }^{23}$.

Pero voces apelan contra ese destino que envuelve en la misma vorágine del tiempo al hombre que es sentir y a las ruinas que son naturaleza muerta. Ya vimos el repudio de Arguijo a una lectio erudita. Más lírica, la voz emocionada de Lope de Vega convoca a esas «máquinas difuntas» para mostrarles su más íntima e intransferible tragedia personal:

Vivas memorias, máquinas difuntas, que cubre el tiempo de ceniza y hielo, formando cuevas, donde el eco al vuelo solo del viento acaba las preguntas.

Basas, colunas y arquitrabes juntas, ya divididas oprimiendo el suelo, soberbias torres que al primero cielo osastes escalar con vuestras puntas.

Si desde que en tan alto anfiteatro representastes a Sagunto muerta, de gran tragedia pretendéis la palma,

mirad de solo un hombre en el teatro mayor ruina y perdición más cierta, que en fin sois piedras y mi historia es alma ${ }^{24}$.

La voluntad individualizadora de su propia historia avanza un elemento de rebeldía. Pero rebeldía latente, maniatada, lejana todavía a la «hybrys» romántica, que de nuevo retomará el topos de las ruinas con la misma vitalidad que en el Barroco, pero con distinto aliento. Sentado entre las ruinas de Roma, Shelley concibirá su Prometeo desencadenado bajo la inspiración del «vigoroso despertar de la primavera». Sentado entre las ruinas de Roma, Shelley no mira hacia atrás, sino que se siente impulsado hacia el futuro. Pero esa es ya otra historia.

\section{Begoña López Bubno}

23 Ed. cit., I, pág. 184.

24 LOPB DB VEGA, El peregrino en su patria, ed. de J. B. Avalle-Arce, Madrid, 1973, páginas 192-3. 